\title{
Migración MéXico-Estados Unidos: \\ PARADOJA LIBERAL RENOVADA DEL TLCAN
}

\author{
Genoveva Roldán*
}

Fecha de recepción: 02 de septiembre de 2014. Fecha de aceptación: 09 de enero de 2015.

\begin{abstract}
RESUMEN
El objetivo de esta investigación es presentar algunas de las reflexiones más importantes sobre los signos y las repercusiones teóricas y empíricas que en cuanto a la migración de mexicanos hacia Estados Unidos han resultado tras los 20 años del Tratado de Libre Comercio de América del Norte (TLCAN). Es relevante trabajar en esta dirección, en virtud de que uno de sus principales propósitos era reducir el flujo migratorio, pese a que en su estructura formal no está incorporado lo referido a este sistema migratorio, el más grande del mundo. Su exclusión, se "sustentó" en el nuevo aliento tomado por las políticas liberales en cuanto a que la libertad de la movilidad del capital y de mercancías a través de las fronteras nacionales, se acompaña de la búsqueda de la contención de la movilidad laboral, con el respaldo teórico que ofrece el pensamiento neoclásico de la migration hump.
\end{abstract}

Palabras clave: migración, trabajadores, movilidad laboral, política liberal, mercados de trabajo.

Clasificación JEL: F22, J61, R23.

\section{Migration from Mexico to The United States: the Renewed Liberal Paradox of nafta}

\begin{abstract}
This research aims to introduce some significant reflections on the theoretical and empirical trends and repercussions of the migration of Mexicans to the United States that have resulted from 20 years of the North American Free Trade Agreement (NAFTA). It is useful to explore this direction insofar as one of the agreement's main purposes was to reduce migration flows, despite the fact that its formal structure did not refer to this migration system, the largest in the world. This exclusion was made based on the new wave of liberal policy, which said that the free movement of capital and goods across national borders would be accompanied by the containment of labor mobility, a concept theoretically backed by the neoclassical idea of the migration hump.
\end{abstract}

Key Words: Migration, laborers, labor mobility, liberal policy, labor markets.

* Instituto de Investigaciones Económicas de la UNAM, México. Correo electrónico: groldan@unam.mx 


\section{EMIGRATION MEXIQUE-ÉTATS UNIS : LE PARADOXE LIBÉRAL RÉNOVÉ DE L'ALENA}

\section{Résumé}

L'objectif de cette recherche est de présenter quelques-unes des réflexions les plus importantes sur les signes et répercussions théoriques et empiriques qui, en ce qui concerne l'émigration de Mexicains vers les États-Unis, ont découlé des 20 ans d'Accord de Libre échange pour l'Amérique du Nord (alena). Il est important de travailler dans cette direction étant donné qu'un de ses buts principaux était de réduire le flux migratoire, même s'il n'incluait pas dans sa structure formelle ce qui a trait à ce phénomène migratoire, le plus grand du monde. Cette exclusion, "fondée " sur le nouvel élan pris par les politiques libérales visant la liberté de mobilité du capital et des marchandises à travers les frontières nationales, s'accompagne de la recherche de contention de la mobilité des travailleurs, avec l'appui théorique qu'offre la pensée néoclassique de la migration hump.

Mots clés: émigration, travailleurs, mobilité des travailleurs, politique libérale, marchés du travail.

\section{A IMIGRAÇÃO MÉXICO-ESTADOS UNIDOS: O PARADOXO LIBERAL RENOVADO DO TLCAN \\ Resumo}

O objetivo desta pesquisa é apresentar algumas das reflexôes mais importantes sobre os sinais e as repercussōes teóricas e empíricas que, enquanto à imigração de mexicanos aos Estados Unidos, foram resultado depois de 20 anos de Tratado de Livre Comércio da América do Norte (TLCAN). É relevante trabalhar nesta direção, dado que um dos seus principais propósitos era reduzir o fluxo migratório, apesar de que na sua estrutura formal não está incorporado o que se refere a este sistema migratório, o maior do mundo. Sua exclusão se "sustentou" no renovado fôlego tomado pelas politicas liberais no que diz respeito à liberdade da mobilidade de capitais e de mercadorias através das fronteiras nacionais, acompanhada da procura pela contenção da mobilidade laboral, com o respaldo teórico que oferece o pensamento neoclássico da migration hump.

Palavras-chave: migração, trabalhadores, mobilidade laboral, política liberal, mercados de trabalho.

\section{美墨之间的移民问题：北美自由贸易协定的新自由悖论}

摘要:

本文的研究目的是对墨西哥向美国移民问题做出理论和经验分析的思考，这是北美 自由贸易协定实施20年来所产生的一个重大问题。对这一问题的探究非常有益的, 该自贸协定的一个主要目的是减少移民问题。这一结论假设, 是依据自由主义政策 理念, 即资本和货物的跨国自由流动能够抑制劳动力的流动。这一理念在理论上得 到了新古典劳动力流动理论的支持。

关键词: 移民 劳动力 劳动力流动 自由主义政策 劳动力市场 
We want to export more tomatoes and fewer tomato pickers.

Carlos Salinas de Gortari

\section{INTRODUCCIÓN}

Durante las negociaciones para la inclusión de México, en el Acuerdo de Libre Comercio Canadá-Estados Unidos (ALC-EuCAN, 1989), que se convertiría en el Tratado de Libre Comercio de América del Norte (TLCAN-1994), los países miembro de la ALC-EUCAN se opusieron a las sugerencias del gobierno de México que, durante el proceso de negociación, se expresaron en cuanto a que en su estructura formal, quedara incluido el tema migratorio. La negativa fue rotunda, pero con ella no se ignoraba el fenómeno, por el contrario en dicho proceso jugó un papel central el análisis y debate de las características, condiciones e impacto del fenómeno migratorio de mexicanos en el mercado laboral estadounidense, así como las medidas que se deberían aplicar para lograr su inhibición. En ese contexto el objetivo fue impulsar la libre circulación del capital y de las mercancías, mientras que la movilidad del trabajo tuvo un tratamiento inverso. El entonces presidente de México, Carlos Salinas de Gortari, ofreció que con la firma del TLCAN, el país estaría en posibilidades de exportar mercancías y no trabajadores, tal como lo recuerda el epígrafe de este trabajo.

Al llegar a 20 años de vida de ese Tratado, así como transcurridos los plazos establecidos para que la economía mexicana saldara la apertura económica integral ahí convenida, es conveniente y fundamental -lo cual es el propósito de esta investigación- rastrear las huellas e impactos teóricos y empíricos que, en cuanto al flujo migratorio, han estado presentes durante este periodo; el cual se encuentra inmerso en un conjunto de transformaciones que forman parte del modelo de desarrollo instrumentado en el país a partir de los ańos ochenta que, además de institucionalizar la integración con Estados Unidos (EU) con la firma del TLCAN, ha promovido la desregulación, una nueva relación mercado-Estado y mayor flexibilización-precarización de los mercados laborales.

Con el objetivo de avanzar en esa dirección, el trabajo contiene dos apartados: en el primero se recupera el análisis teórico, el paradigma explicativo de las migraciones y porqué la necesidad de detenerlas a través de la integración económica y, en el segundo se presentan las principales tendencias en cuanto a la movilidad laboral de los mexicanos, sus escenarios y particularidades de 
los últimos 20 años; así como la validez científica de las teorías a partir de la revisión de lo acontecido. Por último se presentarán algunas conclusiones.

\section{EL CONTEXTO DEL NUEVO LIBERALISMO, LAS TEORÍAS DE LA MIGRACIÓN Y EL TLCAN}

La ruptura con el modelo de desarrollo surgido de la posguerra, durante los ańos ochenta, dio lugar en EU, entre otros propósitos, el de regular y disminuir el fenómeno migratorio, de origen centenario, que había conocido un gran impulso en las décadas de los ochenta y noventa, al pasar en 1970 de 936 mil a casi 2.5 millones en 1980; y casi duplicarse en 1990 al superar los 4.6 millones (Yerbook of Migration and Remittances, 2014) y que, en sus expresiones cualitativas, había adquirido una configuración más compleja, que la previamente existente, al coexistir una migración circular con una de tipo definitivo, la diversificación tanto de los trabajos a realizar, así como de los puntos de destino y origen.

Este nuevo escenario, aceleró la aprobación de una nueva ley migratoria en el vecino país. El 6 de noviembre de 1986 el presidente Ronald Reagan, firmó la Inmigration Reform and Control Act (IRCA) también conocida como la Simpson-Rodino, la cual resultó un importante antecedente para el contexto y las condiciones en el que se desenvolvería el TLCAN y la migración laboral de mexicanos. Tres aspectos es importante destacar del IRCA y dos de ellos resultaron las dos caras de una misma moneda. Como su nombre lo indica, por un lado, aceptó la regularización de extranjeros indocumentados, más de 2 millones de mexicanos entraron en esa categoría, condicionando la visa de residencia a que el inmigrante se estableciera en el país y suponiendo, erróneamente, que las necesidades de la economía se subsanaban con dicha regularización, además de menospreciar su impacto en el patrón migratorio. Fue la primera y, quizás, la última ley estadounidense que intentó enfrentar las contradicciones generadas, por las necesidades de su economía, con trabajadores del país vecino, asumiendo responsabilidad frente a sus derechos adquiridos.

En este caso, además del aspecto de la regularización de esta ley, también contempló la institucionalización de la discriminación y violencia de parte de las autoridades migratorias (border patrol), hacia los mexicanos. Entre 19871993, IRCA proporcionó la cobertura legal para dosificar el flujo, a toda costa, de los inmigrantes más no para eliminarlo. Del incremento de la violencia contra los inmigrantes mexicanos, dieron cuenta dos Informes sobre violaciones 
a los derechos humanos de los trabajadores migratorios mexicanos en su tránsito hacia los Estados Unidos, presentados por la Comisión Nacional de Derechos Humanos de México en 1991 y 1996.

En ellos se documentó el aumento de agresiones, de golpes con brutalidad que provocaban lesiones irreversibles, la negativa de atención médica en algunos de estos incidentes, los atropellados con vehículos oficiales, el acorralamiento y encajonamiento en barrancos y ríos, los golpes con linternas, macanas, puntapiés o contra las patrullas fronterizas, la tortura mediante el aire acondicionado en tiempos de frío, las agresiones sexuales, el esposarlos con lujo de violencia, el sometimiento a revisiones degradantes, los insultos y, en no pocos casos, mexicanos que perdieron la vida a manos de la policía fronteriza. Las dos caras de la moneda: regularización de un importante número de indocumentados y violencia (CNDH, 1991, 1996).

El tercer aspecto de esta Ley, que es primordial destacar, por su trascendencia e impacto en la misma formulación del TLCAN y en el flujo migratorio, es el expuesto en su sección 601. Ahí se acordó la formación de una Comisión (Sandoval, 2000), que anunciaba la necesidad de alcanzar un nuevo escenario de nivel macro que, en consulta con los gobiernos de México y otros países expulsores de mano de obra, se dieran a la tarea de localizar soluciones que contribuyeran a detener la inmigración no autorizada a EU. Las preguntas que inicialmente se propuso responder la Comisión Asencio, ${ }^{1}$ fueron: a) ¿cuáles son las condiciones que contribuyen a la migración no autorizada? y b) ¿qué iniciativas de desarrollo económico podrían ser tomadas cooperativamente para aliviar las presiones migratorias? Pese a la amplitud de la región a trabajar (el hemisferio occidental), fue en México el país en el que se centró la atención de las investigaciones que se realizaron, en virtud de su importancia en el total del flujo migratorio.

En apoyo a la Comisión, en México, el expresidente Miguel de la Madrid, nombró al Consejo Nacional de Población (Conapo), apoyado por académicos de El Colegio de México, como la contraparte del Program for U.S. Mexican Policy Studies de la Lyndon B. Johnson School of Public Affairs de la University of Texas at Austin, dirigido por Sydney Weintraub y el Center for U. S. Mexican Studies de la University of California at San Diego, dirigido por el doctor Wayne Cornelius. Instituciones que realizaron investigaciones para localizar los vínculos entre la migración, el comercio,

Quien presidió dicha Comisión fue Diego Asencio, exsubsecretario de Estado, de ahí que se le empezó a identificar como la Comisión Asencio. 
la deuda internacional y las inversiones; además de aspectos como la industrialización e infraestructuras fronterizas y el impacto de las migraciones en las perspectivas nacionales hispanas, entre otros temas. Durante tres años se prolongaron sus trabajos y presentaron el informe final, públicamente, en el año de 1990 contribuyendo directamente a los debates que concluirían con la firma del TLCAN. Dicho informe contiene dos conclusiones centrales:

a) "Aunque hay otros factores importantes, la búsqueda de oportunidades económicas es la motivación primaria de la mayor parte de la migración no autorizada a los Estados Unidos.

b) Mientras que el crecimiento económico para la creación de empleos es la solución última para la reducción de estas presiones migratorias, el proceso del desarrollo económico mismo tiende a estimular la migración, a corto y mediano plazos, al levantar expectativas y facilitar la capacidad de la gente para emigrar. El desarrollo y la disponibilidad de nuevos y mejores trabajos en sus países, sin embargo, es la única manera para disminuir las presiones migratorias, con el tiempo" (Sandoval, 2001).

En concordancia con el diagnóstico, las medidas de solución que se propusieron para alcanzar el objetivo de contener la expulsión de fuerza de trabajo hacia EU, contemplaron al comercio amplio entre el país expulsor y el receptor, como la solución de última instancia. Es decir, la recomendación consistió en impulsar una mayor integración económica de los países expulsores con EU, a través de acuerdos de libre comercio. Específicamente, se insistió en que este país debería apoyar las peticiones a las instituciones financieras internacionales de fondos para el mejoramiento de infraestructura en regiones del interior de México, capaces de albergar actividades maquiladoras y remover los impedimentos existentes para la inversión extranjera. Con la apertura comercial y de inversiones se lograría el crecimiento y desarrollo en la economía mexicana, lo cual permitiría contener la migración hacia la economía estadounidense.

La prevalencia del pensamiento neoclásico, en el diagnóstico del fenómeno migratorio, fue evidente. Por un lado se descartó del análisis la variable correspondiente a las necesidades estructurales de la economía estadounidense, de tal manera que la "motivación primaria" de la migración se localiza en las decisiones individuales, que resultan de las diferencias salariales que existen entre los países de origen y de destino y la falta de oportunidades en el sector agrícola. Por ello se propuso el impulso al libre comercio e inversión y con ello se lograría, con el tiempo, la convergencia económica. 
De acuerdo con esta corriente de pensamiento, los flujos migratorios tendrían un comportamiento como el explicado por la teoría de la migration hump. ${ }^{2}$ Autores como Papademetriou (1991), Philip Martin y Edward Taylor (1995, 1996), al discutir sobre los efectos del desarrollo en la migración, han considerado que esta curva se inicia en niveles muy bajos y llega a un punto muy elevado antes de volver a declinar.Generando lo que se ha llamado una joroba migratoria o los efectos diferenciados del proceso de desarrollo sobre la migración, en el tiempo.

La joroba migratoria o migration hump, está basada en tres supuestos básicos, tal como se dice en las conclusiones de la Comisión Asensio: a) comercio y migración son complementarios en el corto plazo, $b$ ) ambos son substitutos en el largo plazo y $c$ ) la duración y amplitud de la joroba migratoria son relativamente pequeños. La hipótesis se sostiene en el argumento de que las transformaciones a las que da lugar la apertura comercial contribuyen a incrementar la migración, por diversas razones, tales como: que por un lado ofrece mejores condiciones a ciertos trabajadores lo cual les permite acumular nuevos recursos para poder emigrar, porque las reformas dan lugar a un desempleo en los sectores menos competitivos ante la apertura, porque la integración comercial genera y desarrolla un sólido sistema de transporte y comunicaciones entre ellos, que reduce los costos de desplazamiento e incrementa el beneficio neto de la migración, además la integración se acompaña de algunos convenios o procesos de reclutamiento de trabajadores y, cuando ya está en marcha el flujo migratorio y en pleno funcionamiento la articulación de complejas redes sociales y familiares, éstas se encargan de mantener el ímpetu de ese flujo migratorio. Todas ellas perderán importancia, con el tiempo, cuando los trabajadores se den cuenta que en su país ya se puede acceder a salarios mejor remunerados. La figura 1, que a continuación se expone, desarrolla lo antes descrito.

En la propuesta teórica de la joroba migratoria también se señala que ésta tenderá a prevalecer, en función de tres factores: a) si las redes promueven migraciones futuras, $b$ ) cuando hay oportunidades laborales en otros países y, c) por los ajustes económicos que acompañan el proceso de liberalización. La teoría se considera consistente, en virtud de la experiencia observada en el proceso de integración europea, en donde se logró la disminución en la migración

Los orígenes de dicha elaboración, algunos autores (Durand y Massey, 2003) la sitúan con Ackerman en 1976, quien planteó la hipótesis de la emergencia histórica de una curva migratoria que los países experimentan cuando se encuentran en un proceso de desarrollo económico. 
Figura 1. Joroba migratoria

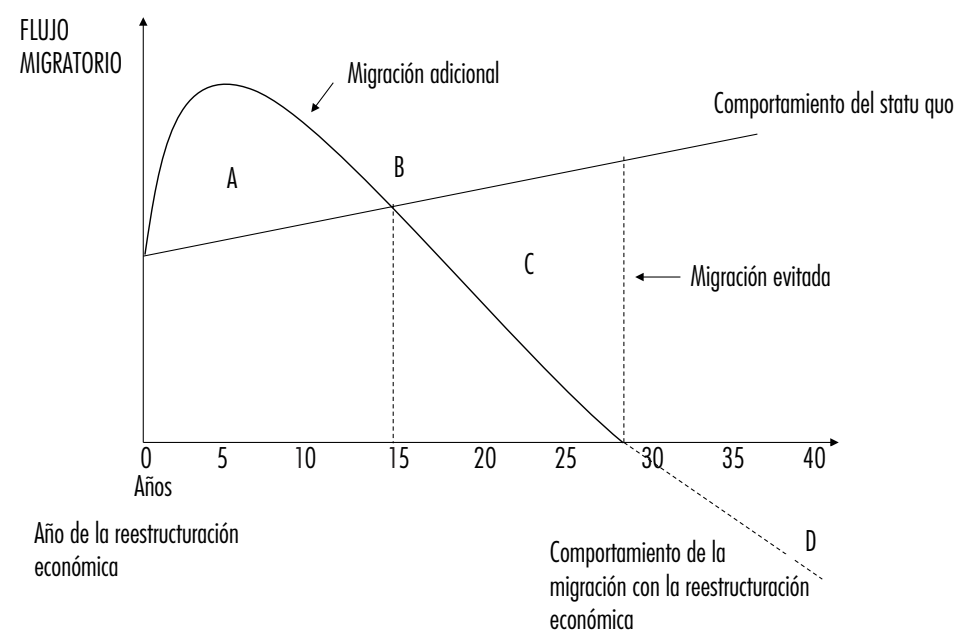

Fuente: Martin (2005).

española, italiana y portuguesa, en un momento posterior a su integración en la Unión Europea (UE).

No es el propósito de este trabajo realizar un análisis comparativo del proceso de integración en la UE con el del TLCAN y, menos aún, hacer una evaluación de aquellas políticas que han buscado disminuir las asimetrías al interior de la UE y que ante el estallido de la crisis de 2008 han puesto en evidencia las debilidades estructurales de la convergencia económica que ha resultado de esa integración; lo cual no cuestiona las diferencias sustanciales que existen entre uno y otro proceso de integración, que hicieron irrepetible la hipótesis de la joroba migratoria en el proceso de integración que surgió con el TLCAN. Mientras que con este último, el instrumento básico utilizado para cerrar la brecha entre los países desarrollados y atrasados, tiene como eje central a las inversiones que fluyen hacia los países expulsores de trabajadores migrantes; en la UE se creó un complejo andamiaje institucional (Fondos Estructurales, Política Regional y Política Social Comunitarias) para reducir algunas de las asimetrías.

De las soluciones que se propusieron por la Comisión Asencio y que posteriormente fueron asumidas por el proyecto del TLCAN, hemos de destacar la existencia de una paradoja, tanto teórica como de política pública. A nivel global se observa que el impulso a la libertad de la movilidad del capital y de las mercancías a través de las fronteras nacionales, se ha visto acompañada de la búsqueda de la contención de la movilidad laboral, ya sea mediante pro- 
yectos de integración, tratados de libre comercio, blindaje de fronteras, políticas migratorias y acciones sociales de índole xenofóbico y racista.

En otros trabajos (Roldán, 2010) hemos insistido en que esta paradoja liberal no tiene un significado metafísico existencial, tal como lo enunciaron Unamuno o Kierkegaard, en la que ésta es producto de la peculiar condición de la naturaleza humana, que es incapaz de aprehender y prever, por la razón lógicamente estructurada, todos los acontecimientos y que es obligada a decidir ante ciertas situaciones aparentemente absurdas en las cuales pone en juego su propio ser, como tampoco parece reflejar una simple contradicción en el discurso lógico, como la famosa paradoja del mentiroso de Epiménides, el cretense.

La paradoja de la postura liberal, frente a la movilidad laboral de las personas que se dirigen hacia mercados laborales de otros países, a pesar de su formulación coherente y, en algunos casos, en apariencia correcta, expresa una postura que no encaja con lo que, en general, se espera que pueda producir el pensamiento liberal. Esta paradoja resulta de que los principios del liberalismo son una expresión de las fuerzas económicas, políticas y sociales que han estado en juego en sus orígenes y estado actual, de ahí sus ambivalencias, oscuridades y presentación no aséptica. Desde la perspectiva teórica el liberalismo económico, históricamente, ha enfrentado la contradicción de cómo respaldar la libre circulación del capital y negar, limitar o acotar, indistintamente, la del trabajo calificado o escasamente capacitado, a condiciones particulares de control y sometimiento.

Este contrasentido es resultado de que, la consolidación de las sociedades modernas se sustentó en el fortalecimiento político, racial, cultural, ideológico, jurídico, territorial y obviamente económico de los Estados-nación, así como en la búsqueda del olvido de sus orígenes multirraciales.Mientras que, simultáneamente, desde su gestación se evidenció que ante las potencialidades del sistema económico, en cuanto a su consolidación y expansión, no le serían suficientes los mercados nacionales de mercancías, capital y trabajo. La movilidad de este último, mantiene una relación directa con la contradicción capital/trabajo de los países receptores, pone en evidencia problemáticas referidas a salarios, condiciones laborales, vivienda, transporte y salud, que son exacerbadas por las posturas más retrógradas y reorientadas como una contradicción trabajo-nativo/trabajo-inmigrante, atribuyendo a estos últimos su inestabilidad económica, política y social.

No es el objetivo de esta investigación hacer un recorrido histórico, de la paradoja existente en el pensamiento liberal y su rechazo moderado o abierto, a la movilidad internacional del trabajo. Baste recordar que el ensancha- 
miento de la inmigración de mexicanos, documentados e indocumentados, reactivó la paradoja liberal, así como el enérgico rechazo de diversos sectores de la sociedad y políticos estadounidenses, que empezaron a referirse a este incremento de la inmigración, como una invasión de ilegales o invasión silenciosa. A ocho columnas en el Herald Examiner de Los Ángeles, desde el 8 de agosto de 1977, se afirmaba que: "El Estado está amenazado por hordas de extranjeros".

La preocupación sobre la naturaleza e impacto del incremento de los inmigrantes indocumentados convocó a grupos religiosos, civiles, étnicos y de minorías, agencias de servicios sociales y a diversos sectores del Congreso, en condiciones en las que la recuperación económica que se logró no fue similar a la de posguerra, ya que dio paso a un amplio periodo de inestabilidad en el crecimiento, el cual necesitaba encontrar "culpables".

Fueron los inmigrantes mexicanos quienes, entre otros, recibieron agudas críticas y se les responsabilizó de algunos de sus males y contradicciones, tales como la tendencia del ingreso familiar hacia el estancamiento, de las tasas salariales bajas, de la delincuencia, de las enfermedades contagiosas y del deterioro de los servicios sociales. Parcial resultaría este análisis, si se obvia el hecho de que no sólo se expresaron manifestaciones de descontento frente a los inmigrantes mexicanos, ya que también se escucharon las voces de granjeros y algunos sectores empresariales, representados en el Congreso, que insistían en la necesidad de abrirse al ingreso de este flujo migratorio, por su bien demostrada capacidad de trabajo.

Ambas posturas tenían poco de novedosas ya que, históricamente, el país de inmigrantes por excelencia ha expresado permanentemente y, en no pocas veces, de forma muy violenta, temores ante la inmigración "excesiva", los cuales no sólo han sido manifestados hacia los mexicanos, fue el caso de la preocupación que provocaba la llegada, a finales del siglo XviII de alemanes.

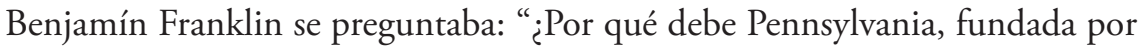
los ingleses, convertirse en una colonia de extranjeros, que serán en breve tiempo tan numerosos que nos germanizarán, en lugar de ser nosotros quienes los anglicisemos?" (Martin, 2007). O por el contrario, cuando en las audiencias congresionales que sobre inmigración se realizaron en 1926, se afirmaba que los agricultores requerían de la mano de obra más barata que existiera y que precisamente era la mexicana la que se encontraba en esa condición (Audiencias del Congreso, 1926).

Estos criterios opuestos continúan presentes y se expresaron cuando en 1971 se retomó el tema en las Audiencias del Congreso, con un verdadero torrente de propuestas para reformar el Acta McCarran-Walter de 1952 y el Acta 
de Inmigración de 1965. En 1972 el diputado Peter Rodino presentó una propuesta legislativa que pretendían convertir en delito el empleo de trabajadores indocumentados y preveía penas para los empleadores, la cual si bien fue aprobada en la Cámara de Representantes fue rechazada por el Senado. El tema provocó grandes debates y puso en evidencia las dificultades para conciliar ambas posturas, dando lugar a lentos procesos legislativos con acciones postergadas, mientras que el flujo migratorio continuaba en ascenso.

El predominio de las posturas antinmigrantes se expresó en 1976, cuando la Ley de Inmigración y Nacionalidad de 1952 fue nuevamente enmendada a partir de la aprobación del Congreso de la Ley pública 94-571, conocida popularmente como proyecto Eilberg Bill (Western HemisphereAct). El presidente Ford firmó la Ley y admitió los efectos negativos que tendría sobre México, ya que estableció un límite numérico de 20 mil visas permanentes de residencia a todos los países del continente americano, reduciendo así la inmigración documentada de mexicanos, en un 60\%. Sin embargo, el resquicio que permitió el continuo crecimiento de la inmigración mexicana fue que no se aceptó ninguna propuesta que se dirigiera a imponer sanciones a la demanda de los patrones estadounidenses de trabajo indocumentado. La enmienda confirmaba el paso libre a su contratación, para ello los patrones utilizaron sus viejas y nuevas redes, además de las construidas por los inmigrantes, permitiendo resolver las necesidades del mercado de trabajo.

Recién aprobada la enmienda se retomó el debate, cuando en 1977 el presidente Jimmy Carter presentó un plan ejecutivo ante el Congreso para "reforzar las fronteras del país", el cual incluía medidas destinadas a complacer los intereses empresariales y suavizar el resentimiento público. A los empleadores les ofrecía mano de obra sin beneficios laborales o derechos para los trabajadores temporales. Al público hostil a los inmigrantes, se prometían métodos más eficaces de control y deportación de los indocumentados (Maciel y Herrera, 1999).

El propósito del anterior y muy rápido recuento, es destacar tanto la existencia como el fortalecimiento, en esas tres últimas décadas del siglo $\mathrm{xx}$, que es cuando se observa un incremento importante de la migración mexicana, del debate y políticas públicas contrarias a la migración, así como el respaldo que encuentran en el pensamiento neoclásico ortodoxo, del cual destacan G. Borjas y O. Stark quienes centran sus investigaciones en los supuestos efectos que la migración tiene para el país receptor, utilizando las herramientas metodológicas de los modelos de Bwagwati, Saajastad, Srinivasan, Ramaswami y Mundell, que a su vez se sostenían en el modelo estándar de Hecksher-OhlinSamuelson. Con el objetivo de analizar, de forma todavía más directa, el mer- 
cado de trabajo del país "huésped" para concluir que son reducidos los efectos que en términos de beneficios genera esta movilidad y que se recogen en el concepto de excedente de la inmigración, el cual resulta de comparar la renta generada por los factores nativos antes y después de la inmigración.

Este enfoque de la elección racional, en donde son los individuos la unidad de análisis, también fue complejizado al incorporar los efectos a escala y las externalidades que redundan en el aumento de los costos de la migración por las diferencias culturales, sociales y formas de vida, así como aquellas que surgen del conocimiento y habilidades del trabajador, es decir, de los niveles de "capital humano" que están involucrados en la movilidad laboral. También suponen que la migración provoca que la remuneración para los inmigrantes pueda ser transferida al país expulsor, por medio de las remesas, lo cual significa una pérdida del producto para el país receptor de los inmigrantes, vale señalar que además se supone que aquella transferencia es de los ingresos totales.

En estos modelos, se empezó a insistir en los aspectos negativos que se provoca con la inmigración tales como: la reducción de los salarios de los trabajadores de similar cualificación, partiendo del supuesto del pleno empleo $y$, en caso de que no exista flexibilidad del mercado laboral, la inmigración atraería un segundo aspecto negativo: el aumento del desempleo. Los resultados de estos modelos han sido cuestionados por investigaciones empíricas que han demostrado que la movilidad laboral internacional no impacta en un aumento de desempleo en los países receptores de esta fuerza de trabajo, así como el hecho de que su impacto, en los salarios, es mínimo, lo cual ha puesto en evidencia, su escaso nivel explicativo de la movilidad laboral internacional.

La "nueva economía" de la movilidad laboral internacional se caracteriza por recoger las propuestas ortodoxas del pensamiento neoclásico. Pese a que mantiene la relación analítica entre migración-desarrollo, reduce la amplitud del análisis a la microeconomía por considerar que las variables de esta relación tienen más que ver con la asociación a nivel micro de la toma de decisiones y la existencia de "fallas" en los mercados que están ligadas a un modo "precapitalista" de producción, por tanto, dichas "fallas", sólo están localizadas a nivel sectorial, local, es decir, son fenómenos que aparecen desconectados de la totalidad económica y que son atemporales.

La movilidad laboral internacional, como mecanismo para diversificar riesgos, conlleva el planteamiento de que las diferencias salariales no son, necesariamente, una condición para que ésta ocurra, todavía más, que aún en ausencia de tales diferencias salariales esta movilidad puede continuar. Se re- 
afirma y profundiza el concepto de elección racional, atribuyéndoselo a la familia, la cual es vista como un "portafolio de inversión", que realiza su elección racional aislada, de acuerdo a las condiciones en las que los fallos del mercado se relacionen con su actividad.

En estos modelos la migración se explica por un extraño entrelazamiento de factores signados por la supuesta racionalidad económica, con tintes voluntaristas, que se expresa en que las familias realizan cálculos de beneficio, que les permiten "elegir con buen criterio", para que los mexicanos que emigren a EU sean aquellos de sus miembros que probablemente les proporcionen más ganancias de renta neta, en donde el "enemigo común" que tiene el núcleo familiar es "toda una distribución de un conjunto de familias".

Esta "racionalidad" económica se entrelaza con una terrible subjetividad que se auxilia de supuestos psicológicos, que resultan ser los principios de la economía marginalista que supone la realización de "contratos implícitos intrafamiliares", la "comparación interfamiliar", la "carencia relativa", entendida ésta como los sentimientos suscitados por las desigualdades existentes entre los grupos. Por ello es que Oded Stark, considera la propuesta de Runciman, en donde es explícita la transferencia a la familia, del egoísmo propio del individuo: "cuantas más personas ven a un hombre que asciende mientras que él no es ascendido, con tantas más personas puede compararse en una situación en la que la comparación le hará experimentar carencia relativa" (Stark, 1993: 147).

Con un desarrollo y profusión de nuevas técnicas econométricas corroboran que se logrará la mayor optimalidad con la libre movilidad de bienes, capital y trabajadores, pero que tengan un alto "capital humano". Estas teorías concluyen que la movilidad del trabajo a empleos que no exigen calificación escolar, no es la óptima. Este rápido recorrido por el pensamiento neoclásico permite afirmar que la paradoja del liberalismo se actualizó y se expresa, en una evidente discriminación contra la movilidad, pero sólo la del "factor" trabajo, que se dirige a empleos que requieren escasa calificación.

Con tal perspectiva teórica, que da cuerpo a las políticas migratorias contemporáneas, se corresponden las soluciones que ofreció el TLCAN en cuanto a la posibilidad de eliminar la exportación de personas y transformar la economía mexicana en exportadora de mercancías, ya que se considera que el flujo de bienes y de recursos financieros entre países, con diferentes dotaciones de factores económicos, es un substituto casi perfecto de la movilidad de la fuerza de trabajo en el corto, mediano y largo plazo, a través de la igualación de los precios de bienes y factores lo que, finalmente, reduce los incentivos que sostienen la migración. El desarrollo económico que permitiría detener la mi- 
gración, pasaba por la apertura comercial y de inversión. Esta fue la solución que ofreció el TLCAN, expresada en el preámbulo del propio Tratado:

"...crear nuevas oportunidades de empleo, mejorar las condiciones laborales y los niveles de vida en sus respectivos territorios".

La integración de México al TLCAN se consideró como un resultado "natural" de su inclusión a las dinámicas mundiales de producción, comercio e inversión. De ahí su aceptación, aunque partiera de supuestos que no reconocían las asimetrías existentes, tanto las de carácter histórico y estructural como aquellas otras que se iban a originar o profundizar como resultado de esta integración.

\section{LAS PRINCIPALES TENDENCIAS DEL SISTEMA MIGRATORIO EU-MÉXICO, EN DOS DÉCADAS DE INTEGRACIÓN}

Acercarse al conjunto de tendencias del sistema migratorio EU-México, en estas dos décadas, rebasa los objetivos de este trabajo. Las aristas que permiten construir su conocimiento son diversas, complejas, multidimensionales e interdisciplinarias. En virtud de los objetivos inicialmente planteados, se privilegian aspectos referidos al propósito central que se pretendía alcanzar con el TLCAN: disminuir sustancialmente el flujo migratorio. De tal manera que se dejan fuera del análisis aspectos relativos a las tendencias de las remesas, de su sentido económico, político, social y cultural, de las políticas migratorias aplicadas en este periodo en ambos países, la problemática de violaciones a derechos humanos en la que se ve envuelta, el significado de la incorporación de población indígena, jóvenes y niños a los flujos migratorios, entre otros.

Hecha la aclaración, y sin perder de vista que las tendencias migratorias mantienen una estrecha relación con la reestructuración del modelo económico que ya supera las tres décadas, el saldo de estos 20 años es que la emigración mexicana hacia EU, lejos de observar una tendencia a su disminución, se ha constituido en parte del sistema migratorio bilateral más importante del planeta, con más de 33.5 millones de personas, un poco más del $35 \%$ de ellas nacidas en México y el 65\% de ascendencia mexicana (Pew Hispanic Center, 2014). El fuerte impulso inicia en los años ochenta, como señalamos al inicio 
Gráfica 1. Migrantes mexicanos en Estados Unidos 1970-2013

(millones)

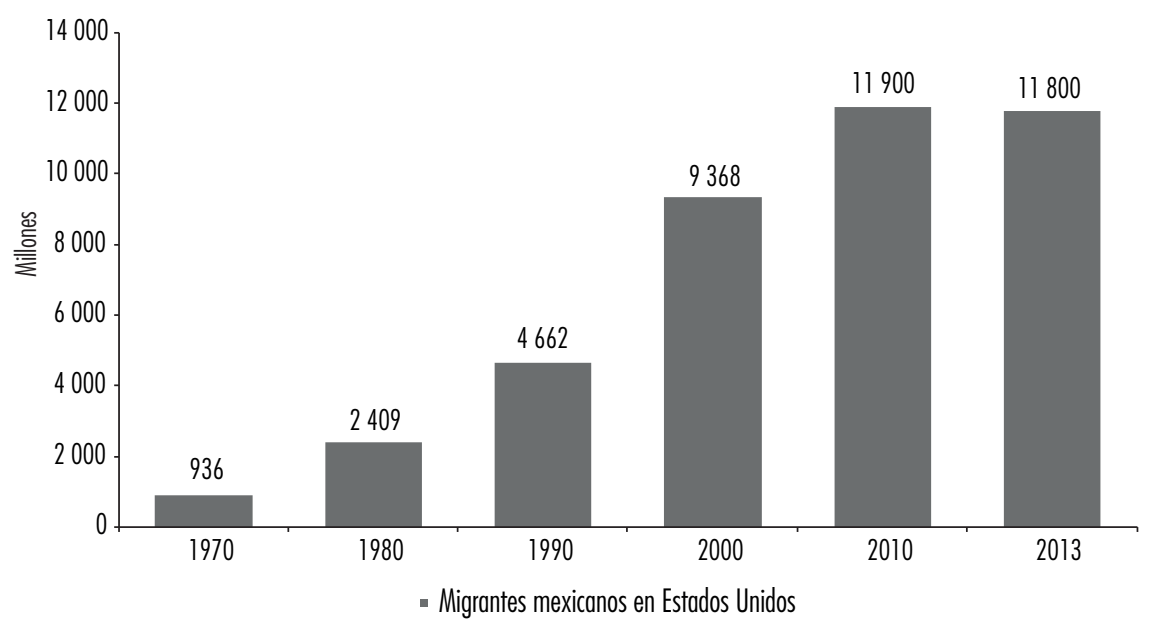

Fuente: elaboración propia con base en el Yearbook of Migration and Remittances, México 2014, BBVA Research.

de este trabajo, y se mantiene hasta el primer lustro del presente siglo; entre 1960-1970 la tasa de crecimiento fue de 53\%, de 1970-1980 alcanzando el nivel más alto al llegar a 157\%, de 1980-1990 de 93\%, de 1990-2000 de $100 \%$ y de 2000 a 2010 de $24 \%$. En cuanto a su incremento en términos absolutos, se puede revisar en la gráfica 1 .

Ese fuerte impulso tiene como explicación primaria, la notable ampliación del mercado laboral estadounidense. En etapas anteriores, se trataba de una migración que fundamentalmente se dirigía a la agricultura, a la cosecha de diversos productos y se encontraba limitada por su carácter temporal o circular. Con una dinámica distinta al plantearse su incorporación al sector servicios y comercio, a la industria de la construcción, manufacturas y disminución en el sector agrícola.

Se trata de actividades que presentan condicionantes a la circularidad y que sumadas al endurecimiento de las políticas migratorias han propiciado que el aumento de la población residente de los mexicanos inmigrantes se acompañe de una caída en la probabilidad de retorno; la cual durante este periodo, se redujo de 55\% en 1987-1992 a 46\% en 1997-2002 (Tuirán, 2006) y a 32\% en el periodo que va del ańo 2005-2010. El incremento de la violencia en la que se ve envuelto todo el fenómeno migratorio, no logró los objetivos propuestos 
en cuanto a su disminución, pero sí afectó la circularidad migratoria. Logrado el cruce a territorio estadounidense, la posibilidad de ir y venir, en plazos más cortos, se limita, ante los riesgos mortales que implica el tránsito fronterizo.

Otro aspecto distintivo del fenómeno migratorio contemporáneo es el incremento de la movilidad indocumentada. En el primer quinquenio de los años ochenta, el número de mexicanos en EU sin papeles era de 18 de cada 100. Mientras que en 2005 sólo 15 de cada 100, contaban con la documentación requerida. Según datos del Pew Hispanic Center (2013), la mayor parte de la migración irregular hacia EU proviene de México, la cual creció de manera importante hacia el 2007, año en el que alcanzó un récord de casi 7 millones de personas, cifra seis veces mayor a la registrada en 1990 (1.4 millones de personas).

Es necesario destacar que después de 2007, la cifra de migrantes irregulares ha descendido hasta llegar a 6 millones de personas para el año 2012; dicha reducción se relaciona con los efectos que la crisis financiera ha tenido en el empleo de la población migrante. Vale señalar que desde diversos foros internacionales, periodísticos y académicos se insiste en no utilizar el concepto de migrante ilegal, categoría que tiene implicaciones jurídicas y políticas muy diferentes a las que caracterizan al inmigrante laboral; el cual no puede ser tipificado como delincuente y menos aún criminalizar su actividad. Ningún ser humano es ilegal por buscar trabajo, su falta es administrativa.

La feminización de la migración ha sido destacada en múltiples investigaciones, la cual revela un importante cambio cualitativo en las tendencias de dicho sistema migratorio. La incorporación de mujeres ya no se realiza mayoritariamente en condiciones de acompañantes, sino de forma autónoma; en 2013, las mujeres representan el $47 \%$ de este grupo de población (Conapo, 2013). Lo cual todavía no se expresa en una tasa similar de la participación femenina en la población ocupada. El 70\% de los mexicanos que trabajaban en EU, en 2005, eran hombres (CPS), para 2013 este porcentaje ha variado, pero no sustancialmente, pues el $61 \%$ de la población económicamente activa continúan siendo varones (Conapo, 2013). De acuerdo con información proporcionada por el Pew Hispanic Center, de los indocumentados mexicanos, el 95\% de los hombres se incorpora activamente al mercado laboral, mientras que de las mujeres indocumentadas, sólo cerca del $54 \%$ lo hace y de las que cuentan con la documentación y que nacieron en México, sólo laboraba el 52\% en 2013. Debemos poner especial atención al hecho de que los patrones de inserción laboral de las mujeres mexicanas, revelan una mayor selectividad (Giorguli y Gaspar, 2006), el 80\% que trabaja, lo hace en actividades en las que se invisibiliza su presencia: limpieza, cuidadoras de 
Gráfica 2. Migrantes mexicanos en Estados Unidos por ocupación y sexo 2013 (\%)

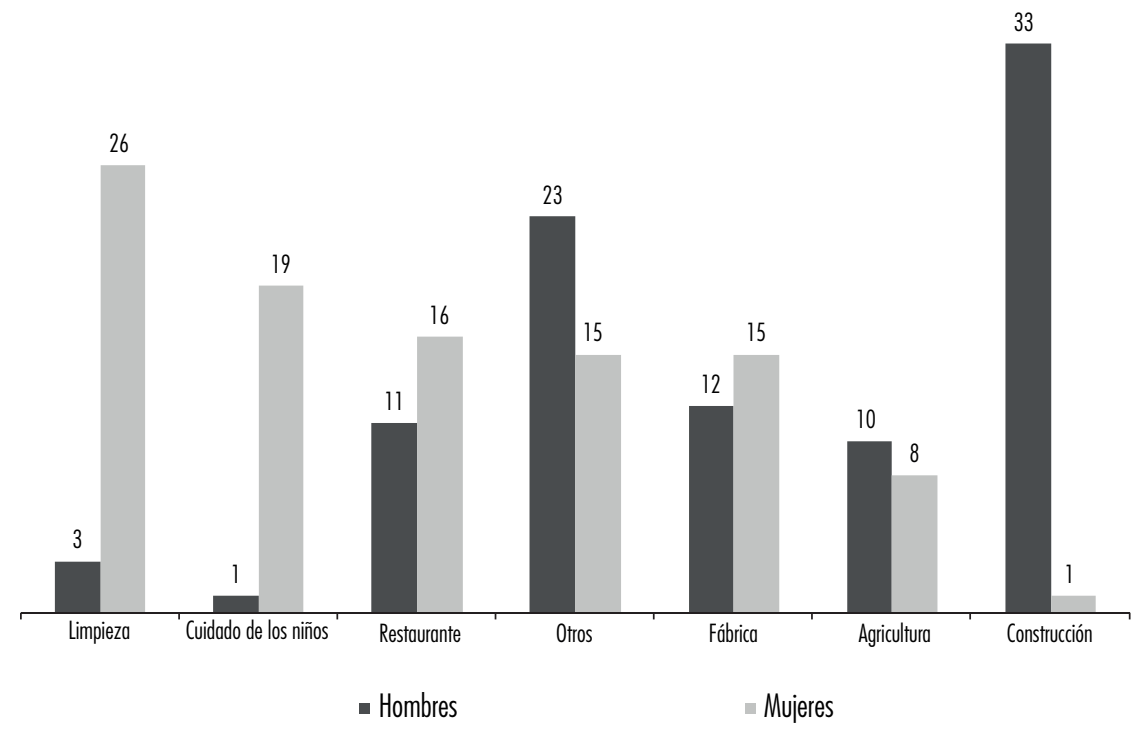

Fuente: Latino Decisions, Everything Latino Politics, 2013.

niños y servicio doméstico, entre otras (veáse gráfica 3) y mantiene una estrecha relación con la reestructuración de conjunto de la economía y sociedad estadounidense.

En cuanto a la nueva geografía migratoria, a la que ha dado lugar esta nueva etapa, destaca el hecho de que tiene una doble direccionalidad. Por un lado los cambios que se localizan en territorio mexicano, así como en el país de destino. En cuanto al país de origen, a los nueve estados "tradicionalmente" expulsores (Guanajuato, Jalisco, Michoacán, Nayarit, Colima, Zacatecas, Durango, San Luis Potosí, Aguascalientes), se han sumado estados que se encuentran en el centro y sur del país: desde el norte de Guerrero, el sureste de Puebla, la zona de la Mixteca, Distrito Federal, Estado de México, Chiapas y Veracruz, han engrosado el flujo migratorio.

Las características centrales de la distribución geográfica de la migración mexicana en EU, desde sus orígenes hasta finales de los ańos ochenta, fue su alta concentración en los estados del sudoeste: California, Texas y Arizona. La reestructuración económica que toma impulso en los ochenta, también se acompañó de cambios en la geografía migratoria, dando lugar a un meteórico proceso de irradiación espacial, pero sin perderse totalmente la concentración 
en los estados originales. De acuerdo con datos de Conapo la mayor parte de los migrantes mexicanos siguen presentes en California (34\%), Texas (20\%) y Arizona (5.1\%), estados tradicionales de llegada de esta población. Sin embargo, encontramos presencia de migrantes mexicanos en otros estados como Illinois (5.3\%), Carolina del Norte (2.2\%), Georgia (2.1\%), Florida (2.1\%), Washington y Nueva York (1.9 y $1.8 \%$ respectivamente).

Observando las tendencias que ha tenido el fenómeno migratorio, resulta evidente que tanto el diagnóstico presentado por la Comisión Asencio, como las expectativas que se generaron por los negociadores del TLCAN en cuanto a la contención del flujo migratorio, se compadecen poco con la realidad. El fracaso es rotundo.

La explicación del aumento en el número de inmigrantes de origen mexicano, en este periodo es multicausal: la finalización de los Convenios Braceros y la consolidación que este fenómeno había logrado en aquellos estados de la República Mexicana, tradicionalmente expulsores, las redes sociales de apoyo tejidas al interior del flujo migratorio, la generalizada y profunda crisis del sector agropecuario que orilló a la incorporación de población de otros estados a este flujo. Causas que encuentran su explicación última en una renovada y creciente incapacidad estructural de la economía mexicana para ofrecer empleo y mejores salarios a su población.

Todas esas condiciones, finalmente, pueden ser agrupadas o atribuidas al contexto económico mexicano, a una cara de la moneda. Sin embargo, en las causalidades que detonan el fuerte incremento de los flujos migratorios, desde una perspectiva opuesta al paradigma liberal así como a sus nuevas expresiones, se encuentran las transformaciones en el mercado laboral estadounidense. Las cuales están inmersas, en las penetrantes modificaciones económicas, sociales y políticas que generó la crisis de los años setenta que se expresaba a nivel mundial, la cual había marcado el fin del largo proceso de crecimiento económico de posguerra.

Estos cambios en los mercados del trabajo, entre otros, han sido de consecuencias trascendentes para la clase obrera nativa e inmigrante que los componen y que se convirtieron en el sostén de la recuperación. Transformaciones que hacia los años ochenta, con la recuperación, impulsaron los mercados de trabajo estadounidense, logrando que éste mantuviera una dinámica generadora de empleos, pese a la inestabilidad en el crecimiento.

Como señala Castells (2003: 250) en la década de los ochenta se incrementó el número de puestos de trabajo en casi $20 \%$; actividad que se mantuvo, aunque a un ritmo menor, en la década siguiente. La mayor concentración de la actividad económica y el empleo, en el sector servicios, la mayoría de 
ellos de tiempo parcial y no sindicalizados. Con una importante incorporación de mujeres, reorganizó a la fuerza de trabajo que había sido relegada de la industria manufacturera, dejando libres aquellos empleos más desvalorados y de baja calificación escolar en ese sector y que, empezaron a ocuparse mayoritariamente con trabajadores migratorios mexicanos, documentados o indocumentados. El nuevo sector servicios de alta tecnología, además de demandar a trabajadores especializados y bien pagados, requirió una considerable cantidad de trabajadores mal remunerados tanto nativos, como inmigrantes, profundizando la estratificación de la fuerza laboral.

El crecimiento del empleo en EU, en el llamado sector servicios significó que, entre 1979-1993, se crearon sólo en ese sector, 23.8 millones de nuevos puestos de trabajo. Solamente en California durante la década de los ochenta se crearon medio millón de empleos en el sector de limpieza (janitors), la mayoría de ellos de medio tiempo. También se generaron empleos altamente especializados, ya que en 1992, 10 de las 30 principales compañías de alta tecnología de la información en EU estaban asentadas en California. "Cerca de 1 500 de los 2500 negocios de electrónica más grandes del país se localizan aquî" (Siegel, 1995: 153). En este diferente y nuevo esquema, quien particularmente destacó como generador de nuevos empleos, a un ritmo acelerado, fue San Diego, California; en el periodo 1973-1979, el ritmo de su generación fue de más de 5\% anual y para 1980, la cifra fue de más del $4 \%$ (Cusminsky, 1995).

Condiciones que se extendieron a otros estados de la Unión Americana, lo cual permitió a esta economía tener la posibilidad de absorber la mayor parte del incremento natural en la población económicamente activa (PEA), de reubicar a la mayoría de las personas desplazadas de la industria manufacturera, además de dar lugar al aumento del volumen y heterogeneidad que caracteriza a la inmigración en general y particularmente a la mexicana que, en estos años, se convirtió en el principal abastecedor de fuerza de trabajo barata, aseveración afirmada en el Anuario Estadístico del Servicio de Inmigración y Naturalización (INs, por sus siglas en inglés) en 1986, la cual pasó a desplazar a la inmigración de origen europeo, particularmente a la procedente de Alemania. El incremento de la inmigración no se desenvuelve en detrimento del empleo nativo, como lo sugiere el pensamiento neoclásico y los detractores de la inmigración; por el contrario, han sido complementarios, tal como se corrobora en la gráfica 2.

Los supuestos del nuevo liberalismo para la interpretación de las migraciones, tienen un contenido profundamente ideológico y político, que conduce al señalamiento de que el fenómeno migratorio es el resultado de decisio- 
Gráfica 3. Migración mexicana y tendencia de la tasa de empleo en Estados Unidos (1990-2012)

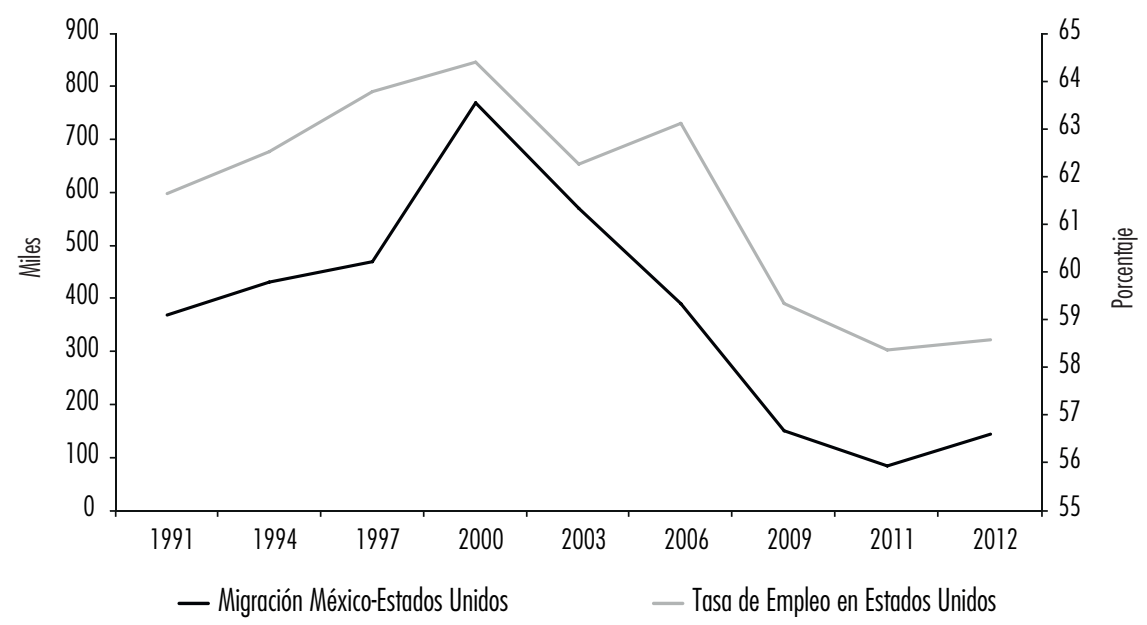

Fuente: elaboración propia con base en datos del Pew Hispanic Center, 2013, Labor Force Statistics from the Current Population Survey, 2014 y el Yearbook of Migration and Remittances, BBVA Research, 2014.

nes individuales, de tal manera que el detonante de la migración se localizará en los países de donde son originarios estos trabajadores, en este caso México, y como tal, hay que enfrentarlas. La voluntad de migrar como principio ontológico, la ponderan como un punto de partida que, en última instancia, explica la realidad y la libertad de elegir migrar sin preceptos o impulsos externos que los presione o acote hacia el desplazamiento, sólo el que les es intrínseco: la racionalidad económica.

El predominio del sentido común en la sociedad en general, así como en los propios migrantes, ha simplificado las causas desfigurando sus orígenes y haciendo a un lado la profunda complejidad que permea su evolución y actuales expresiones. Como señala Saskia Sassen (2007), si bien muchos inmigrantes consideran que la migración es resultado de sus decisiones personales, la opción de migrar en sí misma es un producto social. El pensamiento neoclásico desaparece las relaciones desiguales y de dependencia que dominan en la economía internacional en general y en particular la que existe entre México-EU, las cuales lejos de erradicarse se han profundizado en esta etapa de globalización, integración y apertura comercial.

Desde los países hegemónicos se definen las direcciones, peculiaridades y principales manifestaciones de los procesos de reproducción capitalista, como 
es el caso de la emigración de una fuerza de trabajo originaria de otros países y que pasa a ser una contribución para su desarrollo. "Más que un simple juego de oferta y demanda, como pregonan los artífices del modelo neoliberal, este proceso se inscribe en las estrategias del capital monopolista internacional para súper explotar la fuerza de trabajo de las periferias con un costo invaluable para los países y regiones de origen (Delgado y Márquez, 2011: 16). Las condiciones de complementariedad-subordinada de la economía mexicana hacia la estadounidense, también se expresan en el tema migratorio.

El TLCAN, es parte de un modelo de crecimiento en el que se le otorgó al comercio-inversión y su liberalización un papel fundamental, convirtiéndolos en la supuesta "locomotora del desarrollo", que permitiría allegarse de inversión, nueva tecnología y disminuir el flujo migratorio, tal como se había diseñado desde la Comisión Asencio. Ahora bien, el éxito del cambio en la especialización comercial a partir de este modelo, que incluye al TLCAN, no ha tenido una correspondencia con el conjunto de la economía, particularmente con algunas variables, como la del empleo. De tal manera que la evaluación del éxito exportador exige más cautela, así como la necesidad de establecer la relación entre expansión de las exportaciones y crecimiento económico, lo cual permite revisar la capacidad de arrastre del sector exportador del conjunto de la economía, así como su incidencia en la heterogeneidad interna de la economía y las debilidades históricas del mercado laboral.

La fragilidad del vínculo que ha existido entre capacidad exportadora y crecimiento, ha tenido un fuerte impacto en la absorción de la fuerza de trabajo mexicana, salarios y distribución del ingreso; particularmente se han profundizado las debilidades de dicho mercado: con el incremento del desempleo abierto, con una elevación mínima de los salarios reales del sector formal, débil crecimiento de la productividad laboral, reducción de la cobertura de la seguridad social, ampliación de la brecha salarial entre los ingresos laborales de los sectores formal e informal y la consecuente intensificación del flujo migratorio. Estos se han convertido en argumentos muy sólidos para explicar la continuidad e incremento de la movilidad de trabajadores mexicanos a nivel internacional, que ha respondido a una demanda originada desde EU de trabajadores para empleos de baja calificación.

Comparto los señalamientos de Raúl Delgado Wise y Humberto Márquez Delgado (2007: 13), quienes sostienen que el proyecto instrumentado en México: "Lejos de responder a un modelo de libre comercio benéfico para ambos países, esas políticas han desencadenado nuevas relaciones de producción que a su vez, entrañan una nueva modalidad de intercambio desigual. Éstas confieren a México el papel de proveedor especializado de recursos naturales 
y, sobre todo, de fuerza de trabajo barata"; o como se señala en el Informe de Cepal, sobre Migración y Desarrollo (diciembre de 2008: 12) el cual, desde una perspectiva regional, afirma que "Latinoamérica se ha transformado en un 'exportador' de personal al extranjero".

Todavía hasta el año de 2005, cada hora, salían 45 mexicanos del país, hacia EU; vale preguntarse, tal como lo hace el Informe sobre Migración y Desarrollo Humano del PNud (2006-2007): ¿migrar, es una decisión en libertad o es la única opción disponible? Las encuestas aplicadas a los migrantes permiten responder que lo hacen porque las asimetrías salariales, la segmentación y la exclusión del mercado de trabajo en México, no les ofrece muchas opciones. No es una decisión en libertad, porque entre lo que se elige, no se encuentra en condiciones de igualdad. Si a lo anterior se incorporan factores como la vecindad, historicidad y existencia de redes, tanto de empleadores como de los migrantes, nos explicaremos porque un número importante de mexicanos ha optado por migrar.

Si bien en 2012, según cifras del Pew Hispanic Center, el flujo de mexicanos se detuvo, e incluso hay referencias sobre su descenso, las causas de este acontecimiento corroboran que los flujos migratorios son detonados por las condiciones generadas en la economía y sociedad estadounidenses, que son complementarias con las condiciones de atraso y escasa capacidad de absorción de los mercados laborales en México. De tal manera que la explicación de la disminución del flujo no se localiza en la existencia de un importante crecimiento económico, del aumento de los niveles salariales o de mejores oportunidades de empleo en México; sino por la fragilidad de los mercados de trabajo en EU con el estallido de la crisis de 2008 y el endurecimiento de las políticas migratorias a fin de protegerlos.

\section{CONCLUSIONES}

La emigración mexicana hacia EU se ha constituido en el vínculo migratorio bilateral más importante del planeta. Realidad que se encuentra muy alejada, de los propósitos trazados en la Comisión Asencio, en el TLCAN, o de un comportamiento migratorio como el señalado en la teoría de la migration hump.

El acelerado crecimiento de la migración documentada e indocumentada, en estos 20 años, si bien encuentra explicación en las transformaciones producidas en la economía mexicana, por la firma del TLCAN, su catalizador lo constituyen las modificaciones estructurales que ha observado el funcionamiento de la economía estadounidense, de las características que asumió la segmenta- 
ción de su mercado laboral y estratificación de su fuerza de trabajo nacional e inmigrante, a partir de la crisis de los ańos setenta, las cuales se convirtieron en el detonante del fenómeno migratorio de mexicanos hacia EU. Estos procesos son los que explican el incremento y mayor complejidad que ha adquirido el flujo migratorio.

La gravedad de las condiciones económicas, políticas y sociales en las que se desenvuelve la migración de mexicanos hacia Estados Unidos, exige una revisión de conjunto de los modelos de crecimiento aplicados en ambas economías, que no soslayen instrumentalmente el fenómeno como en 1994 y que, se sustenten en una reflexión más profunda sobre sus causas y consecuencias.

\section{BIBLIOGRAFÍA}

BвvA Research y Conapo (2014), Yearbook of Migration and Remittances, México.

Castells, Manuel (2003), La era de la Información. Vol. 1. La sociedad Red, México, Siglo XXI Editores.

Cepal (2008), Migración y Desarrollo. El caso de América Latina y el Caribe, Informe de las Actividades de Difusión: Talleres Nacionales y Seminario Internacional.

CNDH (1991), Informes sobre violaciones a los derechos humanos de los trabajadores migratorios mexicanos en su tránsito hacia los Estados Unidos, México.

(1996), Segundo Informe sobre las Violaciones a los Derechos Humanos de los Trabajadores Migratorios Mexicanos en su Tránsito hacia la Frontera Norte, al cruzarla y al internarse en la Franja Fronteriza Sur Norteamericana, México D.F., enero, 203 pp.

Consejo Nacional de Población (Conapo), www.conapo.gob.mx

(2013), La Migración Femenina Mexicana a Estados Unidos. Tendencias Actuales, México, Conapo.

Delgado W., Raúl y Humberto Márquez Covarrubias (2007), "El papel de la fuerza de trabajo barata mexicana en el mercado laboral transnacional", en Revista Problemas del Desarrollo, Revista Latinoamericana de Economía, vol. 38, núm. 149, Instituto de Investigaciones Económicas, México unaM.

(2011), "Una perspectiva del sur sobre capital global, migración forzada y desarrollo alternativo", en Revista Migración y Desarrollo, Vol. 9, Número16, Red Internacional de Migración y Desarrollo, Universidad Autónoma de Zacatecas, México. 
Delgado W., Raúl y Margarita Favela (2004) (coords.), Nuevas tendencias y desafios de la migración internacional México-Estados Unidos, México, $\mathrm{H}$. Cámara de Diputados, LIX Legislatura, Universidad Autónoma de Zacatecas, CIICH, UNAM, Porrúa.

Durand, J. y Massey Douglas (2003), Clandestinos. Migración México-Estados Unidos en los albores del siglo XXI, México, Universidad Autónoma de Zacatecas y Miguel Ángel Porrúa.

Giorguli S., Silvia y Gaspar S. Olvera (2006), La migración mexicana y el mercado de trabajo estadounidense. Tendencias, perspectivas y ¿oportunidades?, México, Consejo Nacional de Población (Conapo), Secretaría de Gobernación.

Informe sobre las violaciones a los derechos humanos de los trabajadores migratorios mexicanos en su tránsito hacia la frontera norte, al cruzarla y al internarse en la franja fronteriza sur norteamericana (1991), México, Comisión Nacional de Derechos Humanos.

Maciel, R. David y María Herrera S. (1999), Cultura del otro lado de la frontera, México, Siglo XXI Editores.

Martin, Philip (2005), "Mexico-US Migration", NAFTA Revisited: Achievements and Challenges, Institute for International Economics, Washington, D.C., disponible en http://www.iie.com/publications/chapters_preview/332/08iie3349.pdf

(2007), "Creación y recreación de Estado Unidos", en Inmigrantes, el continente móvil, Vanguardia, Dossier, núm. 22, enero/marzo, España.

Organización Internacional de las Migraciones (OIM) (2014), Informe sobre las Migraciones en el Mundo 2013, Ginebra, Suiza, oIm.

Papademetriou, Demetrios G., (1991). "Employer sanctions and U.S. labor markets: first report" en Immigration policy and research, rept. 2, xxIv, U.S. Dept. of Labo, Bureau of International Labor Affairs, Washington, D.C.

PewHispanic Center: www.pewhispanic.org/

Roldán D., Genoveva, (2011). "Las migraciones laborales internacionales y algunos de sus mitos", en Ana María Aragonés (coord.), Mercado de trabajo y migración internacional, Instituto de Investigaciones Económicas, UNAM, México.

Sandoval P., Juan Manuel (2001), "El Plan Puebla-Panamá como regulador de la migración laboral Centroamericana y del Sur-Sureste de México", ponencia presentada en el II Foro Internacional de Información, Análisis y Propuestas sobre Libre Comercio y Asuntos Transfronterizos, organizada por RMALC, 12 de mayo. 
Sassen, Saskia, (2007), Una sociología de la globalización, Editorial Katz, Buenos Aires.

Siegel, Lenny (1995), "Las nuevas tecnologías y la polarización de la fuerza laboral en Silicon Valley", en Rosa Cusminsky M. (coord.), California. Problemas Económicos, Políticos y Sociales, México, Centro de Investigaciones sobre América del Norte, Coordinación de Humanidades, UnAm.

Stark, Oded (1993), "La migración del trabajo", Colección Economía y Sociedad del Trabajo, núm. 63, Madrid, España, Ministerio del Trabajo y Seguridad Social.

Tuirán, Rodolfo (2006), "La migración mexicana hacia Estados Unidos: las reformas en puertas y los retos futuros", en Papeles de Población, Centro de Investigación y Estudios Avanzados de la Población, México, UAEm, pp. 9-32. 
